\title{
ACE-inhibitor induced angioedema masked by nephrotic syndrome
}

\author{
Kenneth Iwuji MD, Hezekiah Sobamowo MD, James Tarbox MD, Rose Egbe MD
}

\begin{abstract}
Angiotensin-converting enzyme (ACE) inhibitors are the leading cause of drug-induced angioedema in the United States because these drugs are widely prescribed for several common medical disorders. Angiotensin-converting enzyme inhibitors cause angioedema in 0.1 to 0.7 percent of recipients. When prescribing ACE-inhibitors to patients, angioedema should always be considered as a potential adverse reaction during treatment.
\end{abstract}

Key words: angioedema, angiotensin-converting enzyme inhibitor, nephrotic syndrome

\section{INTRODUCTION}

Angiotensin converting enzyme (ACE) inhibitor induced angioedema can occur with single or repeated drug exposure. In most cases, angioedema is a diagnosis of exclusion when there is no other explanation for the patient's facial, airway, and extremity swelling. Facial edema involving the upper lips should raise suspicion for angioedema in an atraumatic patient.

\section{CASE}

This is a case of a 40-year-old Caucasian woman with a past medical history of grade II diastolic heart failure, hypertension, hyperlipidemia, type 2 diabetes mellitus, hypoalbuminemia, and nephrotic range proteinuria. She presented to the hospital with a 6-month history of bilateral lower extremity swell-

Corresponding author: Kenneth Iwuji MD Contact Information: Kenneth.Iwuji@ttuhsc.edu DOI: 10.12746/swrccc2016.0416.224 ing, periorbital edema, swelling of the upper lip, and vague generalized abdominal pain. Two months ago she had a similar presentation and was treated in the hospital with diuretics for 3 days and discharged home with moderate resolution of her symptoms. During this hospitalization, she denied any shortness of breath, orthopnea, headache, changes in mental status, vision changes, fever, cough, or chest pain. She admitted to having nausea with no vomiting, vague generalized abdominal discomfort with an approximate 10 pound weight gain, and inability to open her eyes due to periorbital edema.

Relevant physical examination revealed clear lung sounds, normal S1 and S2 heart sounds with no murmurs, no jugular venous distention, and no acute distress. Some positive findings in this patient were periorbital edema, significant swelling of the upper lips, 2+ bilateral lower extremity pitting edema, and mild generalized abdominal tenderness to palpation.

Current medications included bumetanide, codeine/acetaminophen as needed for pain, gabapentin, gemfibrozil, metoprolol, simvastatin, and lisinopril which was increased from $5 \mathrm{mg}$ to $30 \mathrm{mg} /$ day during her last hospitalization. 
Laboratory findings included a normal complete blood count result, serum sodium $143 \mathrm{mmol} / \mathrm{L}$, serum creatinine of $0.9 \mathrm{mg} / \mathrm{dL}$, blood urea nitrogen of $16 \mathrm{mg} / \mathrm{dL}$, total serum protein $5.2 \mathrm{~g} / \mathrm{dL}$, albumin $2.3 \mathrm{~g} /$ $\mathrm{dL}$, hemoglobin A1C 5.2\%, urine microalbumin 440, urine protein $1,040 \mathrm{mg} / \mathrm{dL}$, urine random protein/creatinine ratio 17.4 , and 24 hour urine protein 12,728 mg. Abdominal ultrasound, chest X-ray, and abdominal CT scan showed no acute pathology. Left renal ultrasound guided biopsy showed diabetic nephropathy with nodular glomerulosclerosis.

With intensive diuretic therapy, fluid restriction, and strict intake and output, patient's lower extremities edema resolved, but there was no improvement in the facial, periorbital and upper lips edema. Other causes of the facial swelling were considered. She had a normal chest X-ray, normal ejection fraction on recent echocardiogram, normal serum sodium with improving serum albumin and urinary protein. Review of her medications indicated that the patient had been on lisinopril $5 \mathrm{mg}$ per day for renoprotection from diabetic nephropathy which was recently increased to 30 mg during the last hospitalization. Two days after this increase, she started noticing the leg swelling, periorbital edema and upper lips swelling. Angiotensinconverting enzyme inhibitor induced angioedema was suspected and the lisinopril was discontinued.

Twenty four hours after discontinuation of the lisinopril, her facial swelling, periorbital edema and upper lips swelling completely cleared. Complements C3, C4, C1 esterase inhibitor assay (functional and quantitative) and $\mathrm{C} 1 \mathrm{q}$ level were tested for hereditary and acquired angioedema. All these results came back normal. Patient was discharged home the next day, and lisinopril was added to her allergy list.

\section{Discussion}

\section{Epidemiology}

Angiotensin-converting enzyme inhibitors are the leading cause of drug-induced angioedema in the United States because they are widely prescribed for several common medical problems. Angiotensin- converting enzyme inhibitors cause angioedema in 0.1 to 0.7 percent of recipients. ${ }^{1-3}$ This percentage may seem low for a drug adverse effect; considering that 40 million patients in the United States are taking some form of ACE-inhibitor, it makes this adverse effect not uncommon. ${ }^{1}$

\section{Pathophysiology}

Angiotensinogen, a prometabolite that is produced by the liver, is converted to angiotensin I by renin in the kidneys. Angiotensin converting enzyme metabolizes angiotensin I to angiotensin II in the lungs. Angiotensin II helps regulate blood pressure by acting as a vasoconstrictor. It binds to angiotensin II receptors in the vasculatures and causes vasoconstriction resulting in an increase in the blood pressure. Angiotensin II also inactivates bradykinin, a nine amino acid peptide that increases capillary permeability and causes vasodilation. Angiotensinconverting enzyme inhibitors prevent the conversion of angiotensin I to II and cause the accumulation of bradykinin. Impaired bradykinin metabolism leads to release of other metabolites, such as nitric oxide and prostaglandin resulting in vasodilation, an increase in vascular permeability, and a decrease in blood pressure. ${ }^{4}$ For reasons not well understood, some patients are prone to developing impaired bradykinin metabolism from ACE-inhibitors that results in angioedema. In these patients, bradykinin levels are high while on ACE-inhibitors and return to normal after withdrawal. ${ }^{1}$

\section{Clinical Presentation}

Angioedema is a nonpitting edema that generally affects the nondependent areas of the body, such as the lips, tongue, face, upper airway and intestinal wall, and causes symptoms, such as diffuse abdominal pain, nausea, vomiting, and diarrhea. With ACEinhibitor induced angioedema, there is no itching or urticaria, and if present, other etiologies need to be investigated. Potential risk factors for ACE-inhibitor induced angioedema include a previous history of angioedema, age older than 65 years, female sex, smoking, African American race, and underlying $\mathrm{C} 1$ esterase inhibitor dysfunction. ${ }^{5-6}$

Angioedema related to ACE-inhibitors can oc- 
cur at the beginning of therapy, during dose increases as in the case of our patient, or at any time during the course of treatment. ${ }^{6,9}$ The severity of angioedema ranges from mild facial and lip swelling to airway obstruction requiring endotracheal intubation. Some fatalities with ACE-inhibitor induced angioedema have been reported. ${ }^{4}$ Whenever a patient has unexplainable symptoms, careful medication review is warranted.

\section{Diagnosis}

Angioedema is a clinical diagnosis made by careful review of the patient history, detailed physical examination, and medication review. Angiotensinconverting enzyme inhibitor induced angioedema still remain a diagnosis of exclusion with most cases resolved after a few days of being off the medication, yet some studies note persistence months later. ${ }^{11}$ Functional and quantitative levels of $\mathrm{C} 1$ esterase inhibitor, $\mathrm{C} 3$, and $\mathrm{C} 1 \mathrm{q}$ could then be ordered to confirm the diagnosis.

\section{Treatment}

Treatment mostly involves supportive care by stopping the causative agent and monitoring the patient very closely for signs of airway compromise and possible cardiovascular collapse. Antihistamines, corticosteroids, and epinephrine are commonly used during acute episodes; however, these medications are often not effective for ACE-inhibitor induced angioedema. ${ }^{12}$ A recent study by Bas et al. showed that icatibant, a bradykinin B2 receptor antagonist, led to a significantly faster resolution of angioedema compared to antihistamine and glucocorticoids. C1 esterase inhibitors, ecallantide (a kallikrein inhibitor), and fresh frozen plasma have also been used effectively in the treatment of ACE-inhibitor induced angioedema. ${ }^{12}$

\section{Conclusion}

Angiotensin converting enzyme inhibitor induced angioedema can occur anytime during the course of treatment with ACE-inhibitors. Prompt rec- ognition and treatment will help minimize the severity and potential life threatening situations that can result.

\section{REFERENCES}

1. Brown NJ, Ray WA, Snowden M, Griffin MR. Black Americans have an increased rate of angiotensin converting enzyme inhibitor-associated angioedema. Clin Pharmacol Ther 1996; 60(1):8-13.

2. Byrd JB, Touzin K, Sile S, et al. Dipeptidyl peptidase IV in angiotensin-converting enzyme inhibitor associated angioedema. Hypertension 2008; 51(1):141-147.

3. Hoover T, Lippmann M, Grouzmann E, Marceau F, Herscu P. Angiotensin converting enzyme inhibitor induced angio-oedema: A review of the pathophysiology and risk factors. Clin Exp Allergy 2010; 40(1):50-61.

4. Kostis JB, Kim HJ, Rusnak J, et al. Incidence and characteristics of angioedema associated with enalapril. Arch Intern Med 2005; 165(14):1637-1642.

5. Marceau F, Hess JF, Bachvarov DR. The B1 receptors for kinins. Pharmacol Rev 1998; 50(3):357-386.

6. Messerli FH, Nussberger J. Vasopeptidase inhibition and angio-oedema. Lancet 2000; 356(9230):608-609.

7. Molinaro G, Cugno M, Perez M, et al. Angiotensin-converting enzyme inhibitor-associated angioedema is characterized by a slower degradation of des-arginine(9)-bradykinin. J Pharmacol Exp Ther 2002; 303(1):232-237. 
8. Quan M. Case study. ACE inhibitor-induced angioedema. Clin Cornerstone 2009; 9 Suppl 3:S34-5.

9. Toh S, Reichman ME, Houstoun M, et al. Comparative risk for angioedema associated with the use of drugs that target the renin-angiotensin-aldosterone system. Arch Intern Med 2012; 172(20):1582-1589.

10. Malde B, Regalado J, Greenberger PA. Investigation of angioedema associated with the use of angiotensin-converting enzyme inhibitors and angiotensin receptor blockers. Ann Allergy Asthma Immunol 2007; 98:57.

11. Nussberger J, Cugno M, Cicardi M. Bradykinin-mediated angioedema. N Engl J Med 2002; 347(8):621-622.

12. Icatibant in ACE-Inhibitor-Induced angioedema. $N$ Engl $J$ Med 2015; 372(19):1866-1868 